\title{
Bauhinia championi (Benth.) Benth. polysaccharides upregulate Wnt/ $\beta$-catenin signaling in chondrocytes
}

\author{
HUITING LI ${ }^{1 *}$, XIHAI LI ${ }^{1 *}$, GUOZHONG LIU ${ }^{2}$, JIASHOU CHEN $^{1}$, XIAPING WENG $^{1}$, \\ FAYUAN LIU ${ }^{1}$, HUIFENG XU ${ }^{3}$, XIANXIANG LIU ${ }^{1}$ and HONGZHI YE ${ }^{1}$
}

\author{
${ }^{1}$ Academy of Integrative Medicine, Fujian University of Traditional Chinese Medicine, Fuzhou, Fujian 350122; \\ ${ }^{2}$ The First Affiliated Hospital of Fujian Medical University, Fuzhou, Fujian 350002; ${ }^{3}$ Fujian Provincial Key Laboratory of \\ Integrative Medicine on Geriatrics, Fujian University of Traditional Chinese Medicine, Fuzhou, Fujian 350122, P.R. China
}

Received July 15, 2013; Accepted October 3, 2013

DOI: $10.3892 /$ ijmm.2013.1527

\begin{abstract}
Bauhinia championi (Benth.) Benth. polysaccharides (BCBPs), extracted from Bauhinia championi (Benth.) Benth., which has been used in traditional Chinese medicine (TCM) for the treatment of osteoarthritis (OA), are the bioactive constituents of Bauhinia championi (Benth.) rattan. However, the molecular mechanisms responsible for their effects on OA are poorly understood. The $\mathrm{Wnt} / \beta$-catenin signaling pathway plays an important role in the proliferation of chondrocytes. In the present study, the effects of BCBPs on Wnt/ $\beta$-catenin signaling in chondrocytes were investigated. BCBPs were obtained by hot-water extraction and identified by the modified high performance liquid chromatography (HPLC) method. Chondrocytes were isolated from the knees of Sprague-Dawley rats and identified by type II collagen immunohistochemistry. The chondrocytes were treated with or without BCBPs for 48 h. Cell viability was evaluated by MTT assay. The mRNA and protein levels of Wnt-4, $\beta$-catenin, Frizzled-2, glycogen synthase kinase (GSK)-3 $\beta$, cyclin D1 and collagen II were detected by western blot analysis and reverse transcription PCR (RT-PCR), respectively. We found that the BCBPs contained at least seven monosaccharides, including D-mannose, rhamnose, D-(+) glucuronic acid, D-(+) galacturonic acid, D-glucose, galactose and arabinose. The cell viability of the chondrocytes treated with 50, 100 and $200 \mu \mathrm{g} / \mathrm{ml}$ BCBPs was significantly higher than that of the chondroctyes in the control group (treated with $0 \mu \mathrm{g} / \mathrm{ml}$ BCBPs). Furthermore, compared with
\end{abstract}

Correspondence to: Dr Xianxiang Liu or Professor Hongzhi Ye, Academy of Integrative Medicine, Fujian University of Traditional Chinese Medicine, 1 Huatuo, University Town, Minhou Shangjie, Fuzhou 350122, P.R. China

E-mail: liuxianxiang@163.com

E-mail: yelin0930@163.com

*Contributed equally

Key words: Bauhinia championi (Benth.) Benth. polysaccharides, signaling pathway, chondrocytes, osteoarthritis the control group, the mRNA and protein expression of Wnt-4, $\beta$-catenin, Frizzled-2 and cyclin D1 in the BCBP-treated groups markedly increased, whereas the mRNA and protein expression of GSK-3 $\beta$ significantly decreased. Of note, the dose of $100 \mu \mathrm{g} / \mathrm{ml}$ BCBPs was more effective than the dose of $50 \mu \mathrm{g} / \mathrm{ml} \mathrm{BCBPs}$ and $200 \mu \mathrm{g} / \mathrm{ml}$ BCBPs. In addition, we found that treatment with BCBPs upregulated the protein levels of collagen II in the chondrocytes. These results indicate that BCBPs upregulate $\mathrm{Wnt} / \beta$-catenin signaling, thus promoting chondrocyte proliferation.

\section{Introduction}

Osteoarthritis (OA), a common disease in many middleto-old-aged individuals, can cause pain and disability. The imbalance of cartilage matrix synthesis and degradation are the main pathological manifestations of OA, resulting in cartilage degeneration (1). Chondrocytes are the single cell type in cartilage which express cartilage-specific proteins, such as type II collagen and proteoglycans (2). Hence, enhancing chondrocyte function by promoting chondrocyte proliferation may prove to be beneficial in delaying the progression of cartilage degradation.

The Wnt signaling pathway plays an important role in the regulation of proliferation (3), differentiation and apoptosis (4). The Wnt protein binds to Frizzled family receptors and low density lipoprotein receptor-related protein (LRP)5/6 can activate the Wnt signaling pathway, which results in the activation of dishevelled (Dvl) family proteins. The activation of Dvl leads to the inhibition of glycogen synthase kinase (GSK)-3 $\beta$. Without Wnt signaling, GSK-3 $\beta$ is thought to phosphorylate and consequently induce the degradation of $\beta$-catenin (5). When the kinase activity of GSK-3 $\beta$ is suppressed, nonphosphorylated $\beta$-catenin can accumulate in the cytoplasm and migrate to the nucleus, where it interacts with the T-cell factor (TCF)/lymphoid enhancer factor (LEF) family of transcription factors, thus altering the expression of Wnt signaling target genes $(6,7)$, such as cyclin D1, which plays a key role in the $\mathrm{G} 1 / \mathrm{S}$ transition in the cell cycle and is a positive regulator of the G1/S transition (8).

Bauhinia championi (Benth.) (BCB), a dicotyledonous plant from the genus Bauhinia (Leguminosae), has been used 
for dispelling wind, removing blood stasis, activating blood circulation and relieving pain. The dry rattan of BCB has been widely used for the treatment of OA in traditional Chinese medicine (TCM). Previous studies have shown that polysaccharides have vital biological activities in a number of plants, such as inducing immunomodulatory, anti-tumorigenic and wound-healing effects (9), as well as promoting cell proliferation (10-13). In our previous study, BCB polysaccharides (BCBPs) were shown to induce chondrocyte proliferation by promoting the G1/S transition (19). However, it is yet not clear whether BCBPs promote chondrocyte proliferation by activating the $\mathrm{Wnt} / \beta$-catenin signaling pathway. The aim of this study was to determine whether BCBPs upregulate Wnt/ $\beta$-catenin singaling, thus promoting chondrocyte proliferation. Our results demonstrate that BCBPs upregulate Wnt/ $\beta$-catenin signaling in chondrocytes.

\section{Materials and methods}

Animals. Six four-week-old male Sprague-Dawley (SD) rats were purchased from Slac Laboratory Animal Co. (Shanghai, China). The care and use of the animals in this study complied with the Guidance Suggestions for the Care and Use of Laboratory Animals administered by the Ministry of Science and Technology, China (14).

Extraction, isolation and purification of BCBPs. Dried BCB powder $(100 \mathrm{~g})$ was extracted with petroleum ether twice at $60-70^{\circ} \mathrm{C}$. Subsequently, the extracted $\mathrm{BCB}$ powder was dried again, extracted with $1,000 \mathrm{ml} 80 \%$ (v/v) ethanol, filtered, dried in air and extracted three times with boiling distilled water $(1: 25, \mathrm{w} / \mathrm{v})$ for $5 \mathrm{~h}$. The extraction solution was filtered and concentrated to $5 \%$ of the original volume with a rotary evaporator under reduced pressure. Following deproteination using the Sevag method (chloroform:1-butanol, 4:1) (15), the condensed solution was precipitated by gradually adding $100 \%$ ethanol until the final concentration reached $80 \%$. Following overnight precipitation, the precipitates were centrifuged and washed with 15-20 ml of ethanol, acetone and ether. The BCBPs were obtained by freeze-drying the precipitates, as previously described (16).

Analysis of monosaccharide composition. BCBPs (20 mg) were hydrolyzed with $1 \mathrm{ml} 4 \mathrm{M}$ trifluoroacetic acid (TFA) at $110^{\circ} \mathrm{C}$ for $2 \mathrm{~h}$ in a small sealed ampoule filled with nitrogen. After being returned to room temperature, the hydrolysate was neutralized with $0.6 \mathrm{M} \mathrm{NaOH}$. A total of $200 \mu \mathrm{l}$ of stocked standard solution $(2 \mathrm{mg} / \mathrm{ml})$ or hydrolyzed BCBP solution was mixed with $200 \mu 10.6 \mathrm{M} \mathrm{NaOH}$ and $400 \mu \mathrm{l} 0.4 \mathrm{M}$ methanol solution of 1-phenyl-3-methyl-5-pyrazolone (PMP), and kept in a water bath at $90^{\circ} \mathrm{C}$ for $70 \mathrm{~min}$. After being cooled to room temperature, $0.3 \mathrm{M} \mathrm{HCl}(400 \mu \mathrm{l})$ were added and allowed to react with the mixture. Finally, each resulting solution was extracted with $1 \mathrm{ml}$ chloroform three times and filtered through a $0.45-\mu \mathrm{m}$ membrane for high performance liquid chromatography (HPLC).

BCBPs were analyzed on a HPLC system (Agilent 1200; Agilent Technologies, Santa Clara, CA, USA), an Ultimate ${ }^{\mathrm{TM}}$ XB-C18 column (4.6x250 mm, $5 \mu \mathrm{m}$; Welch Materials Inc., Ellicott City, MD, USA) and a UV detector. The analysis conditions were as follows: mobile phase A:B, 82:18 (A, $0.1 \mathrm{M}$ phosphate buffer; $\mathrm{B}$, acetonitrile); $\mathrm{pH} 6.7$; flow rate, $1.0 \mathrm{ml} /$ min; injection volume, $20 \mu \mathrm{l}$; UV detector, WL $245 \mathrm{~nm}$; column temperature, $30^{\circ} \mathrm{C}$. D-mannose (Man), rhamnose (Rham), D-(+) glucuronic acid (GluUA), D-(+) galacturonic acid (GalUA), D-glucose anhydrous (Glc), galactose (Gal) and arabinose (Ara) were analyzed as the standard substances, as previously described (17).

Isolation, culture and identification of chondrocytes. The SD rats were sacrificed by cervical dislocation and the bilateral knee joints were peeled off under sterile conditions. The articular cartilage was cut out, and rinsed three times in PBS (HyClone, Logan, UT, USA) containing penicillin and streptomycin. The cartilage was cut into $1 \mathrm{~mm}^{3}$ sections, transferred onto a dish with $0.2 \%$ collagenase II (Sigma, St. Louis, $\mathrm{MO}$, USA) and incubated in a $37^{\circ} \mathrm{C} 5 \% \mathrm{CO}_{2}$ incubator. Supernatant fluid was collected every $1.5 \mathrm{~h}$, then centrifuged for $5 \mathrm{~min}(1,000 \mathrm{rpm})$, and the precipitate was resuspended in DMEM containing 10\% FBS, $50 \mathrm{mg} / \mathrm{l}$ vitamin C, $100 \mathrm{U} / \mathrm{ml}$ penicillin and $100 \mu \mathrm{g} / \mathrm{ml}$ streptomycin (HyClone). The cells were cultured in a $25 \mathrm{~mm}^{2}$ culture flask and placed in a $37^{\circ} \mathrm{C}$ $5 \% \mathrm{CO}_{2}$ incubator after adjusting the cell density $\left(3 \times 10^{5} / \mathrm{ml}\right.$; termed P0). The cells were subcultured when they reached $80-90 \%$ confluence, as determined under a microscope. Subcequently these cells were named P1, P2 and P3, as previously described (18). The P2 chondrocytes were identified by type II collagen immunohistochemistry.

Cell viability assay. A total of $100 \mu 15 \times 10^{4} / \mathrm{ml}$ chondrocytes were plated in a 96-well and cultured for $24 \mathrm{~h}$. They were then treated with $0,50,100$ and $200 \mu \mathrm{g} / \mathrm{ml} \mathrm{BCBPs}$ for $48 \mathrm{~h}$. Subsequently, $20 \mu 10.5 \%$ MTT (Sigma) were added to each well, followed by incubation for $4 \mathrm{~h}$ at $37^{\circ} \mathrm{C}$. The purple-blue MTT was dissolved in $150 \mu \mathrm{l}$ DMSO with shaking for $10 \mathrm{~min}$. The absorbance was measured at $490 \mathrm{~nm}$ on an ELISA plate reader (Model EXL800; BioTeK, Winooski, VT, USA).

Western blot analysis. Following treatment with BCBPs, protein was extracted from chondrocytes using lysis buffer on ice, and protein was then measured using the BCA assay. Protein $(20 \mu \mathrm{g})$ was separated on a $10 \%$ SDS-PAGE gel and transferred onto PVDF membranes. The membranes were blocked for $3 \mathrm{~h}$ at room temperature in 5\% non-fat dried milk, and incubated with primary antibodies against Wnt-4, $\beta$-catenin, Frizzled-2 (Santa Cruz Biotechnology, Inc., CA, USA), GSK-3 $\beta$ (Cell Signaling Technology, Inc., Beverly, MA, USA ), cyclin D1, collagen II (Bio-Word Technology, Natong, China) and $\beta$-actin (Santa Cruz Biotechnology, Inc.) overnight at $4^{\circ} \mathrm{C}$ with rocking. The membranes were incubated horseradish peroxidase (HRP)-conjugated secondary antibody (Zhongshan Goldenbridge Biotech, Beijing, China) at room temperature. The ECL method was used to make the signal visible and $\beta$-actin was used as the internal control.

RNA extraction and reverse transcription PCR (RT-PCR). Total RNA was isolated using TRIzol reagent (Invitrogen, Grand Island, NY, USA). RNA $(1 \mu \mathrm{g})$ was reverse transcribed to cDNA according to the instructions provided by the manufacturer. The obtained cDNA was used to determine the 

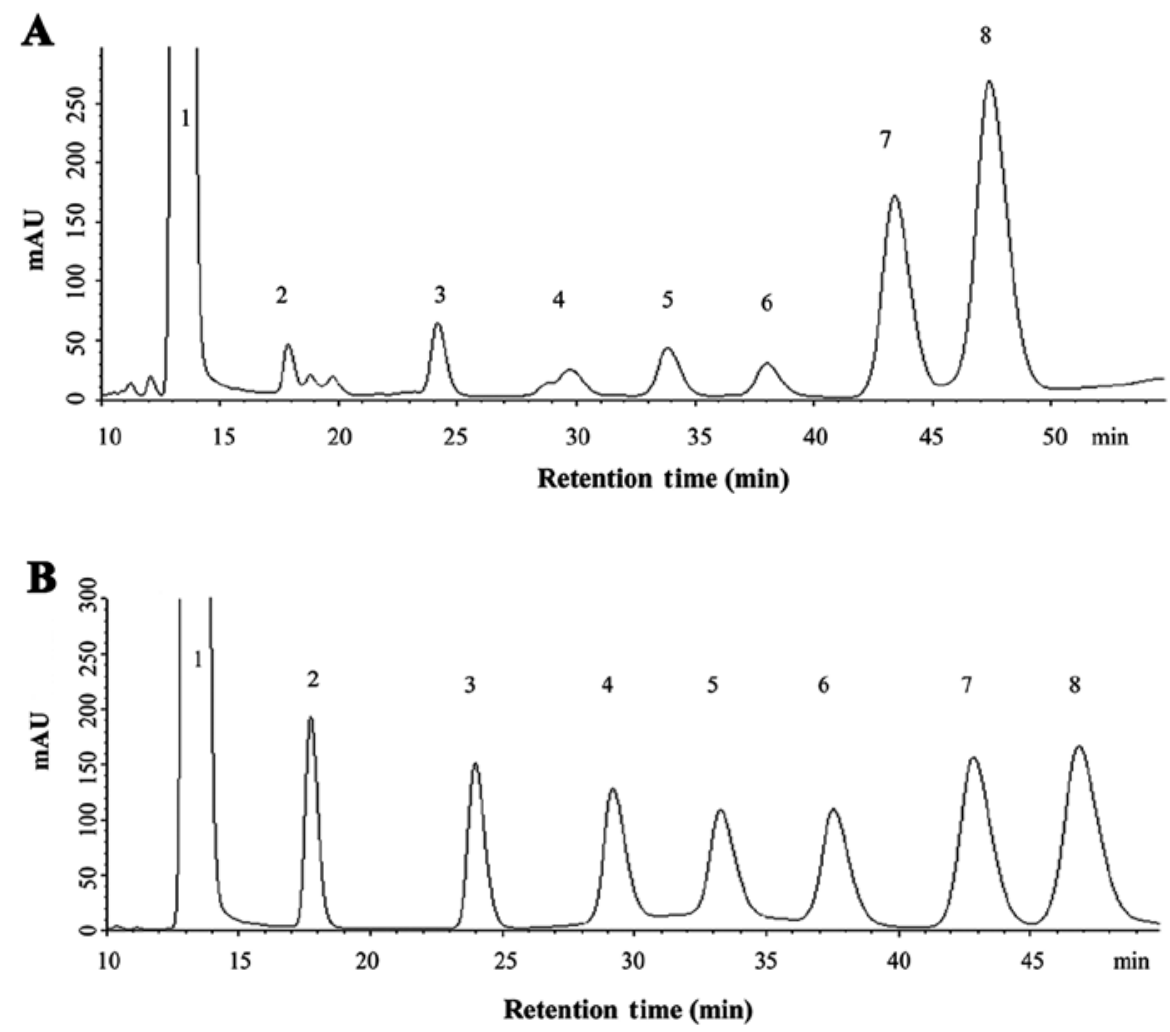

Figure 1. (A) The high performance liquid chromatography (HPLC) chromatograms of composition monosaccharides of Bauhinia championi (Benth.) Benth. polysaccharide (BCBP) hydrolysate. (B) Chromatograms of 1-phenyl-3-methyl-5-pyrazolone (PMP) derivation of standard samples. Peaks: 1, PMP; 2, D-mannose (Man); 3, rhamnose (Rham); 4, D-(+) glucuronic acid (GluUA); 5, D-(+) galacturonic acid (GalUA); 6, D-glucose anhydrous (Glc); 7, galactose (Gal); and 8, arabinose (Ara).

Table I. Sequence of the primers used for RT-PCR in this study.

\begin{tabular}{ll}
\hline Gene & \multicolumn{1}{c}{ Primer sequence $\left(5^{\prime} \rightarrow 3^{\prime}\right)$} \\
\hline Wnt-4 & \\
Forward & TCA GCC CAC AGG GTT TCC A \\
Reverse & CGC TCG CCA GCA TGT CTT T \\
$\beta$-catenin & \\
Forward & AAG GAA GCT TCC AGA CAT GC \\
Reverse & AGC TTG CTC TCT TGA TTG CC \\
Frizzled-2 & \\
Forward & TCG AGG CCA ATT CGC AGT A \\
Reverse & CAG GAA GGA TGT GCC GAT G \\
GSK-3 $\beta$ & \\
Forward & AAA GTG CAT CGC TGG CTT AT \\
Reverse & GTC GAC GGT TTG TTT CCA AT \\
Cyclin D1 & \\
Forward & AAT GCC AGA GGC GGA TGA GA \\
Reverse & GCT TGT GCG GTA GCA GGA GA \\
Collagen II & \\
Forward & CCA GAG TGG AAG AGC GGA GAC \\
Reverse & CAG TGG ACA GTA GAC GGA GGA AAG \\
$\beta$-actin & \\
Forward & CAC CCG CGA GTA CAA CCT TC \\
Reverse & CCC ATA CCC ACC ATC ACA CC \\
\hline
\end{tabular}

GSK-3 $\beta$, glycogen synthase kinase- $3 \beta$. expression of Wnt-4, $\beta$-catenin, Frizzled-2, GSK-3 $\beta$, cyclin D1 and collagen II; $\beta$-actin was used as an internal control. The primers used for PCR are presented in Table I. The conditions use for PCR were as follows: $94^{\circ} \mathrm{C}$ for $4 \mathrm{~min}, 94^{\circ} \mathrm{C}$ for $30 \mathrm{sec}, 57^{\circ} \mathrm{C} / 60^{\circ} \mathrm{C} / 58^{\circ} \mathrm{C} / 60^{\circ} \mathrm{C} / 55^{\circ} \mathrm{C} / 63^{\circ} \mathrm{C} / 60^{\circ} \mathrm{C}$ for $45 \mathrm{sec}, 72^{\circ} \mathrm{C}$ for $45 \mathrm{sec}$, for 35 cycles. The samples were analyzed by gel electrophoresis (1.5\% agarose) and were examined using a Gel Documentation System (Model Gel Doc 2000; Bio-Rad, Hercules, CA, USA).

Statistical analysis. Data are the means of three measurements and are expressed as the means \pm standard deviation. The data were processed using the PASW package for Windows (version 18.0). Statistical analysis of the data was performed using the Student's t-test and ANOVA. Values of $\mathrm{P}<0.05$ were considered to indicate statistically significant differences.

\section{Results}

Monosaccharide composition of BCBPs. By comparing the retention time of unknown peaks to peaks in the standard samples (Fig. 1B), the BCBPs monosaccharide composition was identified (Fig. 1A), and contained at least seven monosaccharides, including Man, Rham, GluUA, GalUA, Glc, Gal and Ara. Among these, the contents of Ara and Gal were higher than those of the other monosaccharides; the content of Ara was the highest, while the separation of Rham, GluUA, GalUA, Glc, Gal and Ara was easier than that of Man. 

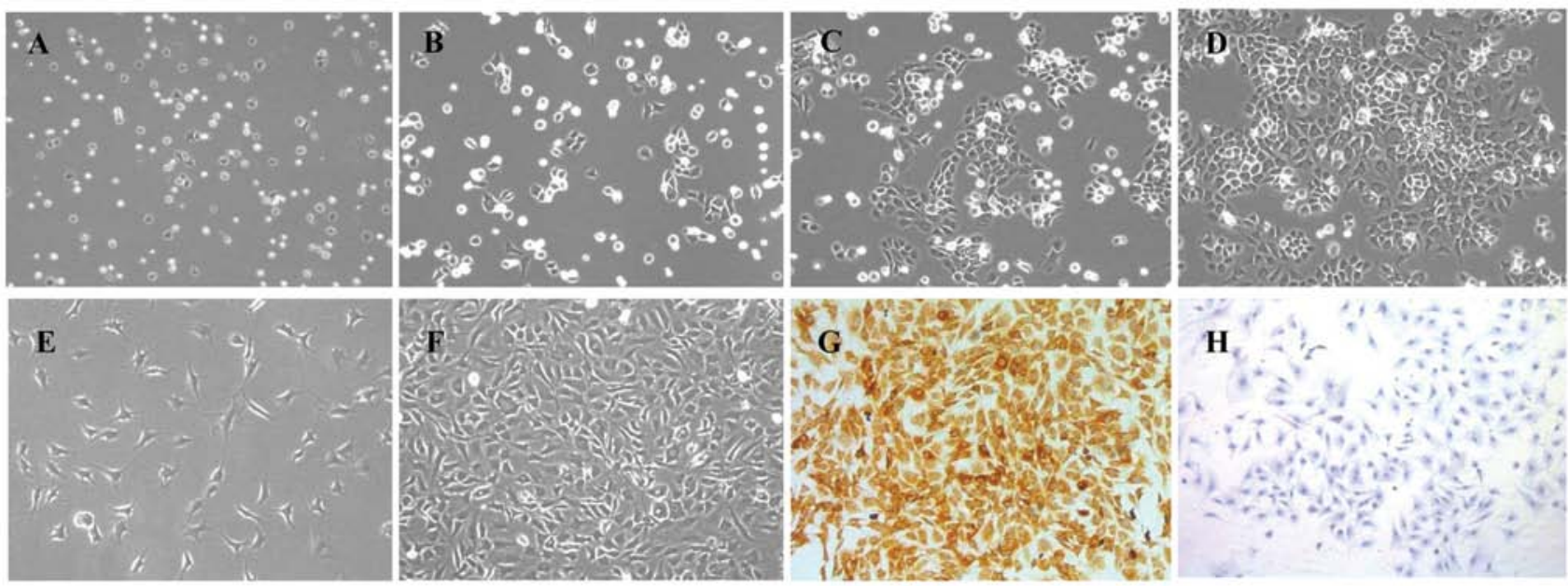

Figure 2. Morphological observation and identification of chondrocytes (magnification, x100). (A) Primary chondrocytes cultured for 24 h. (B) Primary chondrocytes cultured for 3 days. (C) Primary chondrocytes cultured for 5 days. (D) Primary chondrocytes cultured for 8 days. (E) Second passage chondrocytes cultured for 1 day. (F) Second passage chondrocytes cultured for 4 days. (G) Second passage chondrocytes cultured for 4 days, identified by collagen type II immunohistochemistry. (H) Second passage chondrocytes as the negative control identified by collagen type II immunohistochemistry.

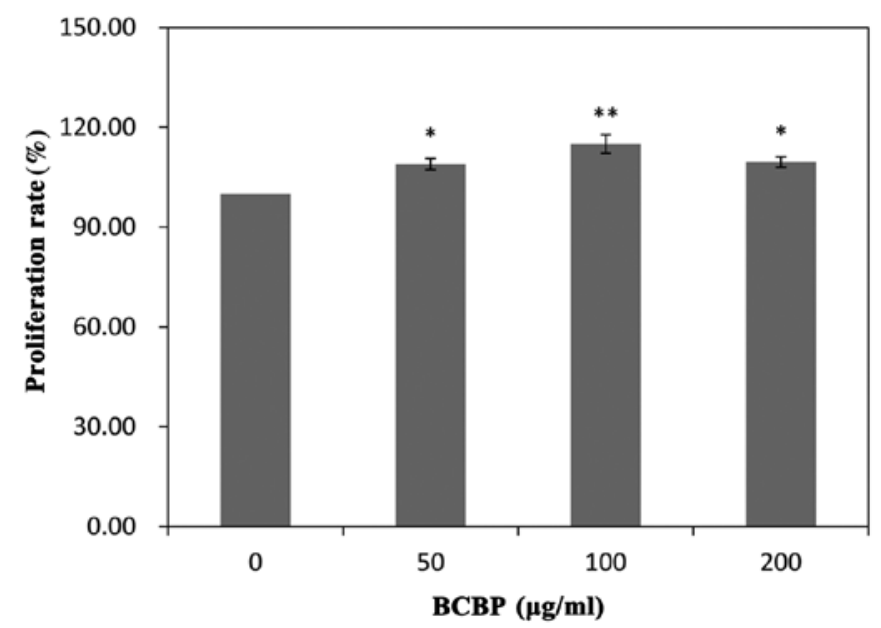

Figure 3. Cell viability of chondrocytes treated with Bauhinia championi (Benth.) Benth. polysaccharides (BCBPs) for $48 \mathrm{~h},{ }^{*} \mathrm{P}<0.05,{ }^{* *} \mathrm{P}<0.01 \mathrm{com}-$ pared with untreated chondrocytes (treated with $0 \mu \mathrm{g} / \mathrm{ml}$ BCBPs).

Morphological observation and identification of chondrocytes. The primary chondrocytes resembled small balls when first suspended in DMEM. After $24 \mathrm{~h}$, the majority of the cells were nestled against the culture flask, and their volumes became larger (Fig. 2A and B). Three days later, the cells grew to be tufted (Fig. 2C). The cells had typical characteristics of chondrocytes, having a 'flagstone' pattern (Fig. 2D) when confluent in a single cell layer. The P2 and P3 chondrocytes grew much more rapidly and became confluent cells within four to five days (Fig. 2E and F). Collagen type II, one of the main secreted proteins in the chondrocyte extracellular matrix, has been commonly used for the identification of chondrocytes by immunohistochemistry. The cytoplasm stained brown represented the positive expression in chondrocytes.

$B C B P$ s promote chondrocyte viability. Chondrocyte viability was detected by MTT assay. As shown in Fig. 3, following treatment with 50, 100 and $200 \mu \mathrm{g} / \mathrm{ml}$ of BCBPs, the cell viability increased by $8.96 \pm 1.66,15.75 \pm 2.75$ and $9.58 \pm 1.59$, respectively when compared with the untreated group (treated with $0 \mu \mathrm{g} / \mathrm{ml} \mathrm{BCBPs})(\mathrm{P}<0.01, \mathrm{P}<0.05)$. These results confirmed that treatment with BCBPs promoted chondrocyte proliferation in a time-dependent manner, as shown in our previous study (19).

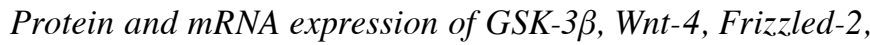
$\beta$-catenin, cyclin DI and collagen II in chondrocytes following treatment with BCBPs. To further determine the effects of BCBPs on the $\mathrm{Wnt} / \beta$-catenin signaling pathway in chondrocytes, we examined the protein and mRNA expression of GSK-3 $\beta$, Wnt-4, $\beta$-catenin, Frizzled-2, cyclin D1 and collagen II by western blot analysis and RT-PCR, respectively. Following treatment with BCBPs, the protein levels of Wnt-4, $\beta$-catenin, Frizzled-2, cyclin D1 and collagen II significantly increased compared with the control group $(\mathrm{P}<0.01, \mathrm{P}<0.05)$. Compared with the control group $(\mathrm{P}<0.01, \mathrm{P}<0.05)$, the protein expression of GSK-3 $\beta$ in the BCBP-treated chondrocytes was significantly downregulated (Fig. 4). The mRNA expression levels of GSK-3 $\beta$, Wnt-4, $\beta$-catenin, Frizzled-2, cyclin D1 and collagen II were similar to their respective protein levels (Fig. 5). Taken together, our results indicate that BCBPs upregulate the protein and mRNA levels of Wnt-4, $\beta$-catenin, Frizzled-2, cyclin D1 and collagen II, and downregulate the levels of GSK-3 $\beta$.

\section{Discussion}

The $\mathrm{Wnt} / \beta$-catenin signaling pathway plays an important role in a number of cellular events, such as cell proliferation, migration and differentiation. The activation of this pathway in different cells and the consequences of such an activation have been extensively discussed. A number of studies have reported that the Wnt/ $\beta$-catenin signaling pathway is necessary for normal and abnormal cell proliferation, such as neural progenitor cells (20), glial cells (21) and a variety of of tumor cells (22). A number of studies have demonstrated that the Wnt/ $\beta$-catenin 
$\mathbf{A}$
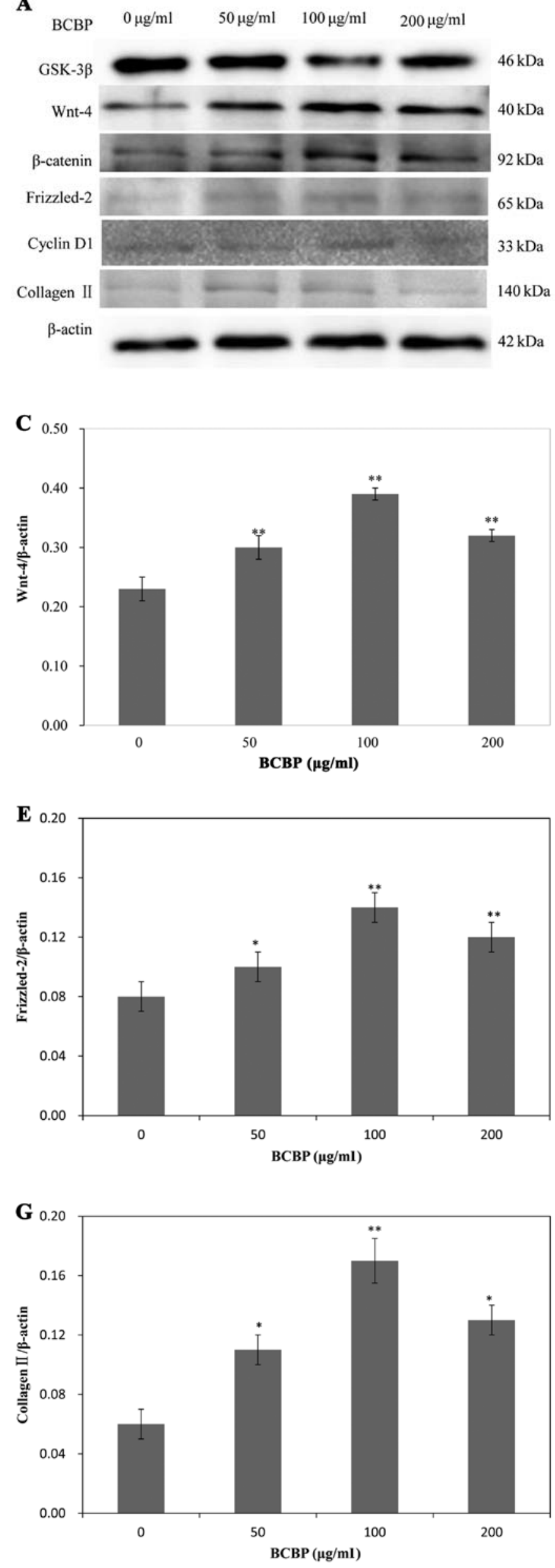
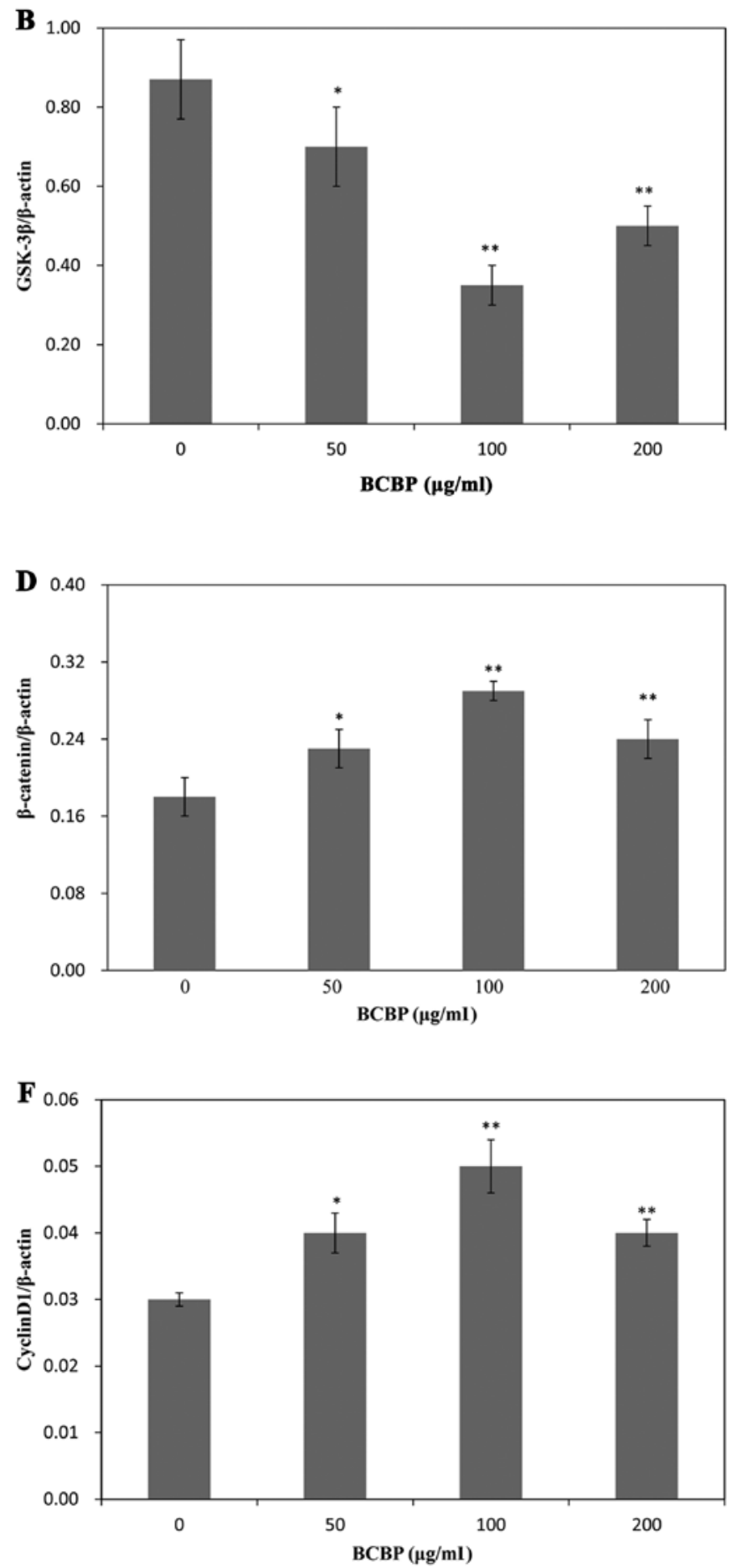

Figure 4. Protein expression of glycogen synthase kinase (GSK)-3 $\beta$, Wnt-4 $\beta$-catenin, Frizzled-2, cyclin D1 and collagen II in chondrocytes. Western blot analysis was used to detect protein expression. (A) Protein levels of GSK-3 $\beta$, Wnt-4, $\beta$-catenin, Frizzled-2, cyclin D1 and collagen II; $\beta$-actin was used as the internal control. (B) Protein levels of GSK-3 $\beta$ in Bauhinia championi (Benth.) Benth. polysaccharide (BCBP)-treated and untreated chondrocytes. (C) Protein levels of Wnt-4 in BCBP-treated and untreated chondrocytes. (D) Protein levels of $\beta$-catenin in BCBP-treated and untreated chondrocytes. (E) Protein levels of Frizzled-2 in BCBP-treated and untreated chondrocytes. (F) Protein levels of cyclin D1 in BCBP-treated and untreated chondrocytes. (G) Protein levels of collagen II in BCBP-treated and untreated chondrocytes. ${ }^{*} \mathrm{P}<0.05,{ }^{* *} \mathrm{P}<0.01$. 
$\mathbf{A}$
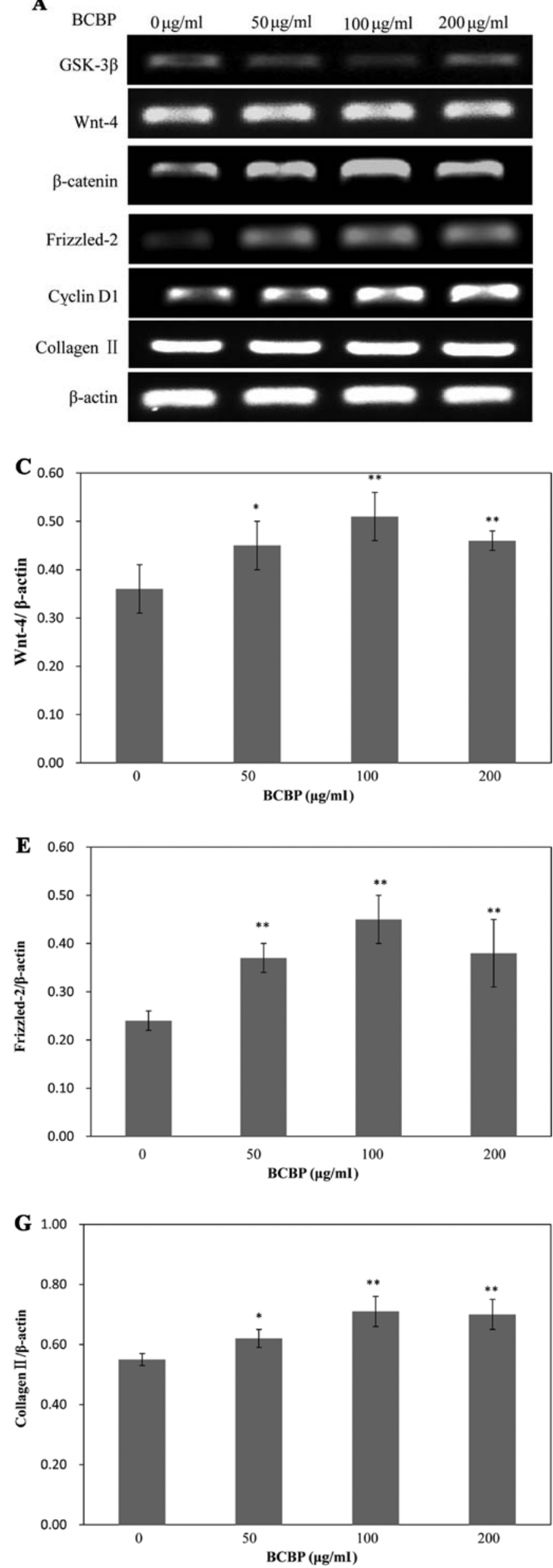

B
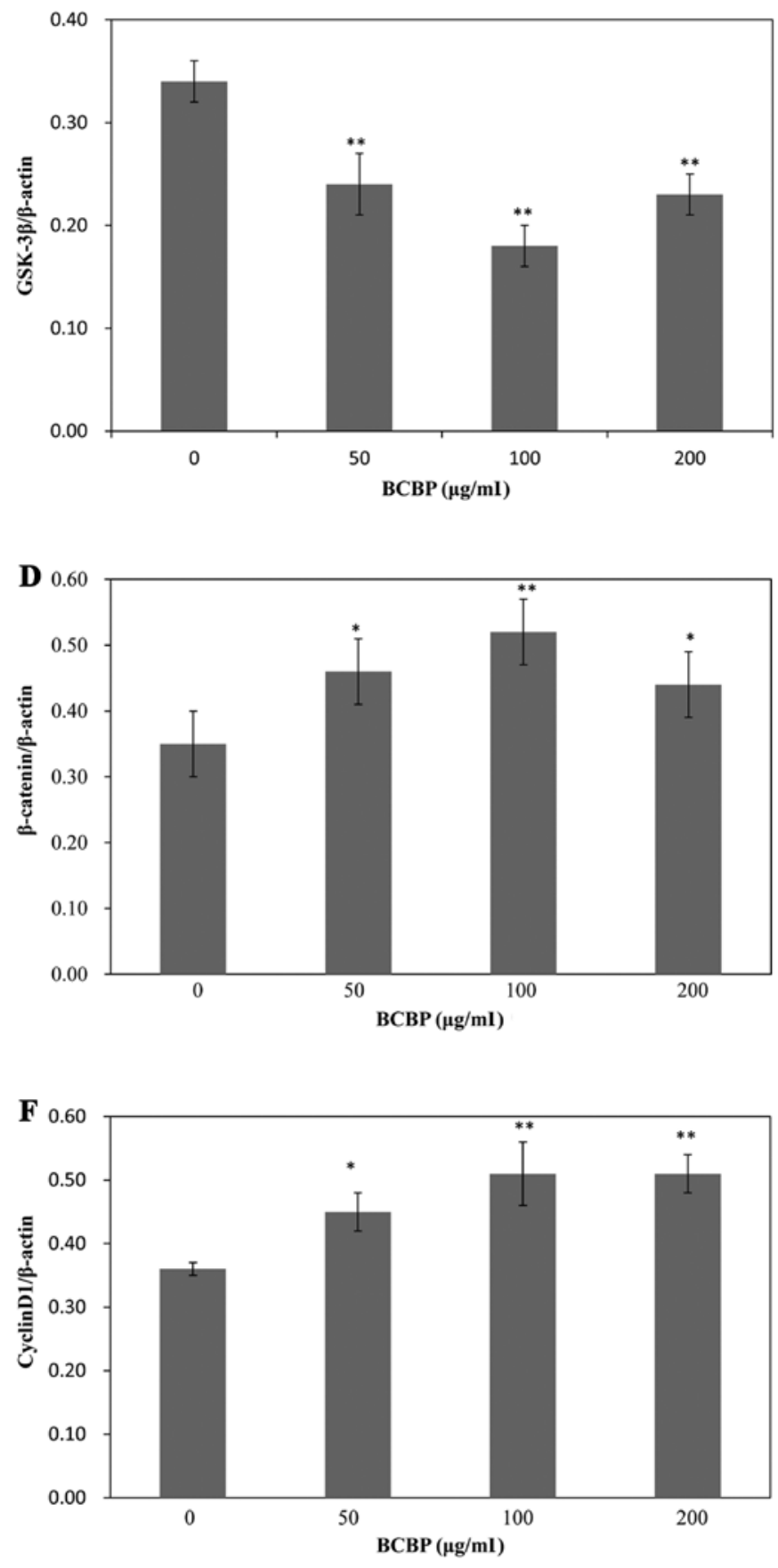

Figure 5. Bauhinia championi (Benth.) Benth. polysaccharides (BCBPs) upregulated the mRNA expression levels of Wnt-4, $\beta$-catenin, Frizzled-2, cyclin D1 and collagen II, downregulated the mRNA expression levels of GSK-3 $\beta$ in chondrocytes. (A) mRNA expression levels of GSK-3 $\beta$, Wnt- 4 , $\beta$-catenin, Frizzled-2, cyclin D1 and collagen II. Reverse transcription PCR (RT-PCR) was used to detect the mRNA expression and $\beta$-actin was used as the internal control. (B) mRNA expression levels of GSK-3 $\beta$. (C) mRNA expression levels of Wnt-4. (D) mRNA expression levels of $\beta$-catenin. (E) mRNA expression levels of Frizzled-2. (F) mRNA expression levels of cyclin D1. (G) mRNA expression levels of collagen II. ${ }^{*} \mathrm{P}<0.05,{ }^{* *} \mathrm{P}<0.01$. 
signaling pathway is closely related to cartilage function, including cartilage development, chondrocyte differentiation and plays an important role in the progression of OA $(23,24)$. In this study, our results revealed that BCBPs upregulated the protein and mRNA expression of Wnt- $4, \beta$-catenin, Frizzled-2, cyclin D1 and collagen II, whereas BCBPs downregulated GSK-3 $\beta$ expression levels, suggesting that BCBPs activate the Wnt/ $\beta$-catenin signaling pathway, thus promoting chondrocyte proliferation.

Currently, the therapeutic strategies for OA are exercise combined with the use of analgesics and non-steroidal antiinflammatory drugs (25); however, these treatments only focus on alleviating the symptoms, which are mainly pain and inflammation, and fail to obtain good results. Non-steroidal anti-inflammatory drugs have several side-effects, such as gastrointestinal-related toxicities and cardiovascular risks. Corticosteroids are also applied for the treatment of OA, but their substantial toxicities limit long term usage. Chinese herbs have been used in the treatment of OA for thousands of years (26). BCBPs, extracted from $\mathrm{BCB}$ are one of the main effective elements used for OA therapy.

Chondrocytes, the only cell type that is present in mature cartilage, are important to maintain the balance of cartilage matrix synthesis, as well as the function of the articular cartilage. In recent years, certain studies have demonstrated that osteoarthritic chondrocytes have a low proliferative activity $(27,28)$. Thus, promoting chondrocyte proliferation may be an efficient method for the treatment of OA. In our previous study, we demonstrated that BCBPs promoted chondrocyte proliferation (19); however, the precise molecular mechanisms responsible for the effects of BCBPs on chondrocyte proliferation have not yet been fully elucidated. In this study, we investigated the mechanisms responsible for the effects of BCBPs on the $\mathrm{Wnt} / \beta$-catenin signaling pathway in chondrocytes to build a scientific foundation for the use of BCBPs in the treatment of OA.

The Wnt/ $\beta$-catenin signaling pathway plays a crucial role in the processes of cell proliferation and differentiation (29), the early stage of cartilage formation, chondrocyte differentiation and endochondral bone formation. The key factor of the Wnt/ $\beta$-catenin signaling pathway is the stable accumulation of $\beta$-catenin in the cytosol and its transfer to the nucleus, binding to the transcription factors, TCF and LEF. These factors regulate the expression of cyclin D1, which is an important factor in cell proliferation and differentiation (30). The activation of the Wnt $/ \beta$-catenin signaling pathway activates cyclin D1, accelerating cell cycle progression. Our results demonstrated that BCBPs increased chondrocyte viability, and significantly upregulated the protein and mRNA expression of Wnt-4, Frizzled-2 and $\beta$-catenin in the chondrocytes, whereas the expression of GSK-3 $\beta$ in the chondrocytes was significantly downregulated, suggesting that the BCBPs activated the Wnt/ $\beta$-catenin signaling pathway by inhibiting the activity of GSK-3 $\beta$, causing non-phosphorylated $\beta$-catenin accumulation and transfer to the nucleus, where it interacts with TCF/LEF to enhance the expression of cyclin D1.

In conclusion, our results demonstrated that the activation of the Wnt $/ \beta$-catenin signaling pathway induced by treatment with BCBPs contributed to chondrocyte proliferation. Apart from the Wnt $/ \beta$-catenin signaling pathway, there are multiple signaling pathways controlling the proliferation of chondrocytes. Hence, additional studies are required to explore the cross-talk function of the signaling pathways during the process of chondrocyte proliferation.

\section{Acknowledgements}

This project was financially supported by NSFC (81202912), the Natural Science Foundation of Fujian Province (2011J05074\&2011J01035), the Developmental Fund of Chen Keji Integrative Medicine (CKJ20110003).

\section{References}

1. Pitsillides AA and Beier F: Cartilage biology in osteoarthritislessons from developmental biology. Nat Rev Rheumatol 7: 654-663, 2011

2. Wu Q, Zhu M, Rosier RN, Zuscik MJ, O'Keefe RJ and Chen D: Beta-catenin, cartilage, and osteoarthritis. Ann N Y Acad Sci 1192: 344-350, 2010.

3. Tao HY,He B,Liu SQ, et al: Effect of carboxymethylated chitosan on the biosynthesis of NGF and activation of the Wnt/ $\beta$-catenin signaling pathway in the proliferation of Schwann cells. Eur J Pharmacol 702: 85-92, 2013.

4. Lu W, Tinsley HN, Keeton A, Qu Z, Piazza GA and Li Y: Suppression of $\mathrm{Wnt} / \beta$-catenin signaling inhibits prostate cancer cell proliferation. Eur J Pharmacol 602: 8-14, 2009.

5. Akiyama T: Wnt $/ \beta$-catenin signaling. Cytokine Growth Factor Rev 11: 273-282, 2000.

6. Li X, Peng J, Wu M, et al: BMP2 promotes chondrocyte proliferation via the $W n t / \beta$-catenin signaling pathway. Mol Med Rep 4: 621-626, 2011.

7. Blom AB, van Lent PL, van der Kraan PM and van den Berg WB: To seek shelter from the Wnt in osteoarthritis? Wnt-signaling as a target for osteoarthritis therapy. Curr Drug Targets 11: 620-629, 2010.

8. Vlad-Fiegen A, Langerak A, Eberth S and Müller O: The Wnt pathway destabilizes adherens junctions and promotes cell migration via $\beta$-catenin and its target gene cyclin D1. FEBS Open Bio 2: 26-31, 2012.

9. Schepetkin IA and Quinn MT: Botanical polysaccharides: Macrophage immunomodulation and therapeutic potential. Int Immunopharmacol 6: 317-333, 2006.

10. Yu F, Li X, Cai L, et al: Achyranthes bidentata polysaccharides induce chondrocyte proliferation via the promotion of the G1/S cell cycle transition. Mol Med Rep 7: 935-940, 2013.

11. Gescher K and Deters AM: Typha latifolia L. fruit polysaccharides induce the differentiation and stimulate the proliferation of human keratinocytes in vitro. J Ethnopharmacol 137: 352-358, 2011.

12. Liu H, Fan Y, Wang W, Liu N, Zhang H, Zhu Z and Liu A: Polysaccharides from Lycium barbarum leaves: isolation, characterization and splenocyte proliferation activity. Int J Bio Macromol 51: 417-422, 2012.

13. Yao H, Chen Y, Li S, Huang L, Chen W and Lin X: Promotion proliferation effect of a polysaccharide from Aloe barbadensis Miller on human fibroblasts in vitro. Int J BioMacromol 45: 152-156, 2009.

14. The Ministry of Science and Technology of the People's Republic of China: Guidance Suggestion for the Care and Use of Laboratory Animals, 2006.

15. Sevag MG: A new physical de-proteination method for representation of biologically effective substances-isolation of carbohygrates in chicken-protein and pneumococci. Biochemis Zeitschrift 273: 419-429, 1934.

16. Li X, Zhang $\mathrm{H}$ and $\mathrm{Xu} \mathrm{H}$ : Analysis of chemical components of shiitake polysaccharides and its anti-fatigue effect under vibrational. Int J Bio Macromol 45: 377-380, 2009.

17. Yang Q, Wang S, Xie Y, Sun J and Wang J: HPLC analysis of Ganoderma lucidum polysaccharides and its effect on antioxidant enzymes activity and Bax, Bcl-2 expression. Int J Biol Macromol 46: 167-172, 2010.

18. Li X, Du M, Liu X, Chen W, Wu M, Lin J and Wu G: Milimeter wave treatment promote chondrocyte proliferation by upregulating the expression of cyclin-dependent kinase 2 and cyclin A. Int J Mol Med 26: 77-84, 2010. 
19. Cai L, Ye H, Yu F, Li H, Chen J and Liu X: Effects of Bauhinia championii (Benth.) Benth. polysaccharides on the proliferation and cell cycle of chondrocytes. Mol Med Rep 7: 1624-1630, 2013.

20. Hirsch C, Campano LM, Wöhrle S and Hecht A: Canonical Wnt signaling transiently stimulates proliferation and enhances neurogenesis in neonatal neural progenitor cultures. Exp Cell Res 313: 572-587, 2007.

21. Chen Y, Guan Y, Liu H, et al: Activation of the Wnt/ $/$-catenin signaling pathway is associated with glial proliferation in the adult spinal cord of ALS transgenic mice. Biochem Biophys Res Commun 420: 397-403, 2012.

22. Kang K, Lee KM, Yoo JH, Lee HJ, Kim CY and Nho CW: Dibenzocyclooctadie-ne lignans, gomisins $\mathrm{J}$ and $\mathrm{N}$ inhibit the Wnt $/ \beta$-catenin signaling pathway in HCT116 cells. Biochem Biophys Res Commun 428: 285-291, 2012.

23. Kitagaki J, Iwamoto M, Liu JG, Tamamura Y, Pacifci M and Enomoto-lwamoto $\mathrm{M}$ : Activation of $\beta$-catenin -LEF/TCF signal pathway in chondrocytes stimulates ectopic endochondral ossification. Osteoarthritis Cartilage 11: 36-43, 2003.

24. Andrade AC, Nilsson O, Barnes KM and Baron J: Wnt gene expression in the post-natal growth plate: regulation with chondrocyte differentiation. Bone 40: 1361-1369, 2007.
25. Van Vijven JP, Luijsterburq PA, Verhagen AP, van Osch GJ, Kloppenburg M and Bierma-Zeinstra SM: Symptomatic and chondroprotective treatment with collagen derivatives in osteoarthritis: a systematic review. Osteoarthritis Cartilage 20: 809-821, 2012.

26. Kang M, Junq I, Hur J, et al: The analgesic and anti-inflammatory effect of WIN-34B, a new herbal formula for osteoarthritis composed of Lonicera japonica Thunb and Anemarrhena asphodeloides BUNGE in vivo. J Ethnopharmacol 131: 485-496, 2010.

27. Chan BY, Fuller ES, Russell AK, et al: Increased chondrocyte sclerostin may protect against cartilage degradation in osteoarthritis. Osteoarthritis Cartilage 19: 874-885, 2011.

28. Huang JG, Xia C, Zheng XP, Yi TT, Wang XY, Song G and Zhang B: $17 \beta$-Estradiol promotes cell proliferation in rat osteoarthritis model chondrocytes via PI3K/Akt pathway. Cell Mol Biol Lett 16: 564-575, 2011.

29. Wang C, Yuan X and Yang S: IFT80 is essential for chondrocyte differentiation by regulating Hedgehog and Wnt signaling pathways. Exp Cell Res 319: 623-632, 2013.

30. Bueno MJ and Malumbres M: MicroRNAs and the cell cycle. Biochim Biophys Acta 1812: 592-601, 2011. 